\title{
Técnicas para controle químico de palmeiras invasoras em Unidade de Conservação na região metropolitana de São Paulo
}

\author{
Luiza Gonçalves Lazzaro \\ Ana Beatriz da Silva Cunha de Barros \\ Rejane Esteves \\ Silvana Cristina Pereira Muniz de Souza * \\ Natália Macedo Ivanauskas \\ Instituto Florestal de São Paulo, Divisão de Dasonomia \\ CEP 02377-000, São Paulo - SP, Brasil \\ * Autor para correspondência \\ silvana1souza@gmail.com
}

Submetido em 10/08/2018

Aceito para publicação em 12/02/2019

\section{Resumo}

Espécies invasoras prejudicam as comunidades vegetais autóctones por eliminar diretamente as espécies nativas ou por inibir a sua regeneração. Há evidências de que as palmeiras exóticas Livistona chinensis e Archontophoenix cunninghamiana, que colonizam remanescentes de Floresta Atlântica, ameaçam os processos sucessionais da vegetação natural e, portanto, devem ser controladas. Neste estudo, avaliamos a eficácia do controle químico dessas palmeiras exóticas com o herbicida glifosato. Efetuamos o controle químico por meio da injeção de glifosato (ROUNDUP TRANSORB R 30\%) no estipe de 30 indivíduos de cada espécie, em dosagens variáveis de acordo com o porte das palmeiras. Os sinais de senescência foram ilustrados, descritos e acompanhados semanalmente até a morte de todas as palmeiras, que demorou 18 semanas para L. chinensis e 29 semanas para A. cunninghamiana. O glifosato mostrou-se eficaz para ambas as espécies e recomendado para o controle de palmeiras adultas de grande porte, as quais devem ser priorizadas no manejo, a fim de eliminar as matrizes responsáveis pela oferta de propágulos.

Palavras-chave: Herbicida; Invasão biológica; Manejo adaptativo; Recuperação

\section{Abstract}

Techniques for chemical control of invasive palm trees in protected areas in the São Paulo metropolitan region. Invasive alien species harm native plant communities by directly eliminating native species or inhibiting their regeneration. There is evidence that the exotic palm trees Livistona chinensis and Archontophoenix cunninghamiana, which colonize Atlantic Forest remnants, threaten the successional processes of native vegetation and, therefore, must be controlled. In this study we assessed the efficacy of glyphosate at chemically controlling invasive populations. The herbicide Roundup Transorb R (30\%) was injected into the stem of 30 individuals of each species and the dose was adjusted according to the size of the palm. Senescence symptoms were monitored weekly until all individuals had died, which happened after 18 
weeks for L. chinensis and 29 weeks for A. cunninghamiana. Glyphosate proved to be an effective herbicide for both species. Priority should be given to using glyphosate to eliminate large adult palm trees first, since they are responsible for producing the most propagules.

Key words: Adaptive management; Biological invasions; Herbicide; Rehabilitation

\section{Introdução}

O estado de São Paulo abriga remanescentes de Floresta Atlântica, apesar da intensa fragmentação ocorrida nas últimas décadas (RIBEIRO et al., 2009). Parte desses fragmentos é constituída por florestas secundárias, as quais foram submetidas ao cultivo e/ ou pastoreio durante os últimos dois séculos e depois convertidas em unidades de conservação de proteção integral (LIEBSCH et al., 2008). Esse cenário se repete na região metropolitana de São Paulo, na qual o histórico de uso associado às fortes pressões antrópicas foram responsáveis por diferentes graus de degradação (CATHARINO; ARAGAKI, 2008; DAVIES; SHELEY, 2011).

Um dos principais indicadores da ação humana sobre ecossistemas é a presença de espécies exóticas invasoras em áreas naturais (ZENNI, 2015; ZENNI et al., 2016). São consideradas exóticas as espécies transportadas de uma dada região geográfica para outra em que não ocorreriam naturalmente, independentemente de seu eventual impacto sobre os ecossistemas naturais, sendo o transporte realizado por ação humana intencional ou acidental (LOCKWOOD et al., 2007). Entre as exóticas, são consideradas invasoras aquelas que colonizam e se expandem em ecossistemas nos quais não ocorreriam naturalmente, não fosse a interferência humana (PYŠEK et al., 1995; 2004; WILLIAMSON, 1996; RICHARDSON et al., 2000; AZEVEDO, 2009). No âmbito da Ecologia da Conservação, questão importante é avaliar o impacto das exóticas sobre os ambientes nos quais elas foram introduzidas e, caso necessário, adotar medidas de erradicação e controle (DURIGAN et al., 2013).

Unidades de conservação representam uma das principais estratégias para a conservação da biodiversidade, mas também elas estão suscetíveis a invasões biológicas. Ziller e Dechoum (2013) demonstraram que o número de espécies invasoras registrado em unidades de conservação de proteção integral e de uso sustentável no Brasil é alto e tende a aumentar. Isso porque as atividades humanas fragmentam paisagens e habitat contínuos, o que pode acarretar perda de conectividade entre áreas protegidas, aumentando a vulnerabilidade dessas áreas a vetores de degradação. Distúrbios naturais ou antropogênicos favorecem a invasão por criarem condições ambientais mais adequadas para o crescimento de plantas e por eliminarem as competidoras dominantes e mais vigorosas (RICHARDSON; BOND, 1991). Como plantas invasoras apresentam alta fecundidade e dispersão eficiente (PYŠEK; RICHARDSON, 2008), há aumento da pressão de propágulos dessas exóticas provenientes de ecossistemas degradados e/ou manejados próximo das áreas protegidas, o que resulta no estabelecimento dessas plantas em áreas indesejadas.

De fato, conforme demonstrado por Zenni (2015), regiões mais populosas e com menor área natural remanescente tendem a apresentar maior número de espécies invasoras, como é o caso da Floresta Atlântica. No entanto, a despeito do grau de conservação da vegetação e das fortes pressões antrópicas, os remanescentes florestais exercem papel importante na conservação da biodiversidade da região metropolitana de São Paulo, visto que ainda resguardam rica fonte de propágulos (DAVIES; SHELEY, 2011). Sem o controle das exóticas invasoras dominantes ali existentes, esses remanescentes poderão se tornar fonte de propágulos indesejáveis para o interior das florestas naturais da Serra da Cantareira e da Serra do Mar, replicando o mesmo processo de invasão biológica já documentado para a região metropolitana.

Entre as plantas invasoras já listadas em planos de manejo e demais estudos em áreas protegidas da região metropolitana de São Paulo (PIVELLO; PECCININI, 2002; SOUZA et al., 2009; ARZOLLA, 2009; 2012; PETRI et al., 2018), destacam-se duas 
palmeiras exóticas introduzidas para fins econômicos e/ou paisagísticos: Archontophoenix cunninghamiana (palmeira-australiana) e Livistona chinensis (palmeiraleque). Essas palmeiras apresentam frutos dispersos pela avifauna, o que facilita e amplifica o processo de invasão e aumenta a competição por dispersores com a flora nativa (CHRISTIANINI, 2006; FONSECA; ANTUNES, 2007). Para Condé et al. (2018), as palmeiras exóticas se estabelecem com sucesso pela entrada contínua de propágulos, altas taxas de germinação e rápido crescimento, o que pode levar ao declínio de populações de palmeiras nativas da Floresta Atlântica, como Euterpe edulis L. (palmito-juçara), devido a mecanismos como competição de recursos, polinização diferencial, dispersão de sementes e eficiência de sobrevivência de plântulas.

O grau de severidade da invasão biológica pela palmeira-australiana foi alvo de estudos na Reserva Florestal da CUASO, inserida no campus da Universidade de São Paulo, em São Paulo - SP (MATOS; PIVELLO, 2009). Nesse trecho de Floresta Atlântica, a diversidade foi mais baixa do que a encontrada em outras florestas naturais próximas, resultado, em grande parte, atribuído à invasão biológica pela palmeira-australiana (DISLICH et al., 2002). A população dessa palmeira exótica apresentou taxa de crescimento anual positiva, em detrimento de populações de espécies nativas, e a expansão populacional foi atribuída à intensa frutificação e consequente dispersão por pássaros generalistas, além da baixa exigência quanto às condições de luminosidade e água (ZUPO; PIVELLO, 2007; SOUZA et al., 2016). Propágulos da palmeira-australiana foram registrados na chuva e no banco de sementes, o que também contribuiu para as altas taxas de recrutamento (PETENON, 2006). Os estudos apresentados indicavam que a população de palmeira-australiana tenderia a aumentar, caso práticas de manejo não tivessem sido implementadas (COCESP, 2018).

Baseados nos estudos realizados na CUASO em 2012, foram iniciadas pesquisas sobre a invasão biológica por palmeiras-australianas e palmeirasleque em trechos de vegetação secundária no Parque Estadual Alberto Löfgren (PEAL), em São Paulo - SP. Confirmou-se o processo de invasão, pois as populações das palmeiras exóticas superaram as barreiras reprodutivas e de dispersão, estabelecendo-se com alta densidade de indivíduos em trechos de Floresta Ombrófila Densa (RAMONEDA; SOUZA, 2016; MANFRA; IVANAUSKAS, 2016; SOUZA et al., 2016). Também se constatou que o aumento em densidade de palmeiras invasoras interfere no uso dos habitat pela avifauna de subosque, com recomendação de controle das populações, a fim de evitar a perda de espécies de aves nas assembleias locais (CAMPAGNOLI; ANTUNES, 2017).

Para a restauração da biodiversidade de uma área em recuperação, é preciso considerar modelos que apresentem baixo custo de implantação e benefícios facilmente perceptíveis (ONOFRE, 2009). Essas premissas são a base do manejo adaptativo, que pode ser definido como qualquer forma de manejo que estimula, quando necessárias, mudanças periódicas nos objetivos e protocolos de manejo, em resposta aos dados de monitoramento e a outras novas informações (DURIGAN; RAMOS, 2013).

Há poucas publicações sobre manejo adaptativo de ecossistemas naturais invadidos por palmeiras exóticas (ZENNI, 2010; DECHOUM; ZILLER, 2013), mas métodos de controle mecânico e químico foram descritos para a Reserva Florestal da CUASO (BITENCOURT, 2013). O controle mecânico foi aplicado em larga escala e previa o corte do meristema apical dos espécimes de A. cunninghamiana logo abaixo da região do palmito, de forma a impedir o rebrotamento e ocasionar a morte do indivíduo. No entanto, dificuldades operacionais resultaram no corte das palmeiras na base do estipe, ocasionando clareiras pela queda da palmeira e/ou no processo de picotagem e remoção do material. O controle químico foi aplicado em escala experimental, com a aplicação de herbicidas que tinham como princípio ativo o triclopir e o glifosato, com recomendações da aplicação deste último como alternativa em termos operacionais e econômicos ao corte mecânico (BITENCOURT; PIVELLO, 2013).

Nesse contexto, este estudo experimental tem por finalidade avaliar a eficácia do controle químico para o manejo das palmeiras invasoras Livistona chinensis e Archontophoenix cunninghamiana. Em continuidade 
ao estudo prévio realizado por Bitencourt e Pivello (2013), buscamos avançar nas técnicas de dosagem e de aplicação e na descrição de sintomas de senescência que permitam o monitoramento, a fim de reduzir ao máximo o risco de contaminação ambiental por aplicação de herbicidas em ecossistemas naturais.

\section{Materiais e Métodos}

Realizamos o estudo no Parque Estadual Alberto Löfgren (2327'32'S e 46 38'11'W), zona norte da cidade de São Paulo. Com altitude que varia de 770 a 825 m, o PEAL ocupa uma área de 187 ha contígua ao Parque Estadual da Cantareira. Sua vegetação é constituída por talhões de espécies cultivadas, os chamados arboretos, e por trechos em regeneração nos estádios de sucessão ecológica inicial e médio de Floresta Ombrófila Densa Montana (ARZOLLA, 2012).

Os arboretos foram implantados antes do decreto que instituiu o PEAL como unidade de conservação de proteção integral. Até 1963, o PEAL foi um Horto Botânico Experimental com talhões, glebas e parcelas de plantios monoespecíficos ou com até quatro espécies exóticas consorciadas com espécies nativas, implantados no período de 1925 a 1957. Parcela significativa da vegetação do PEAL ( $42 \%$ da área) ainda é composta por esses arboretos, apresentando diferentes graus de conservação de suas características originais (ARZOLLA, 2012).

Após a conversão do PEAL em unidade de conservação de proteção integral, os tratos silviculturais nos arboretos foram abandonados, dando início a um processo de regeneração natural (restauração passiva), no qual espécimes de plantas exóticas e nativas ocuparam o subosque não só dos próprios arboretos, mas também das áreas de vegetação secundária com floresta ombrófila, visto que os plantios de espécies exóticas com potencial de invasão de ecossistemas naturais não foram suprimidos (SOUZA et al., 2016). A elaboração do plano de manejo desta unidade de conservação (ARZOLLA, 2012) tornou clara a necessidade de planos de controle e/ou erradicação dessas espécies exóticas invasoras no PEAL, com destaque para as palmeiras
Livistona chinensis (palmeira-leque) e Archontophoenix cunninghamiana (palmeira-australiana).

Livistona chinensis (Jack.) R.Br. ex. Mart. é conhecida popularmente como "palmeira-de-leque-dachina", "livistona" ou "palmeira-leque" e é originária do continente asiático (China, Japão, Taiwan, Bonin e Ilhas Ryukyu). Cultivada como ornamental no mundo inteiro, inclusive no Brasil, é frequente em praças e jardins, além do cultivo em vasos (LORENZI et al., 1996; MEEROW, 1991). Palmeira monoica, de 5-15 m de altura, possui caule solitário, ereto, anelado, fissurado, sulcado transversalmente, com poucos remanescentes da base das folhas na região apical, medindo cerca de $20 \mathrm{~cm}$ de diâmetro. Apresenta crescimento lento, mantendo-se acaule quando jovem. As folhas em leque são numerosas, divididas quase até a base em segmentos finos e pendentes, com pecíolo longo e provido de espinhos curvos nas margens e de fibra marrom na base. As inflorescências são ramificadas, densas, dispostas de maneira pendente entre as folhas. Os frutos são ovoides ou elipsoides, glaucos (verdeazulados) e brilhantes, com polpa alaranjada durante a maturação (KOBORI, 2006), amplamente consumidos por aves (NISHIDA et al., 2014). Diferentemente das demais palmeiras, as sementes de Livistona chinensis apresentam alta porcentagem de germinação, de 96 a 99 $\%$, independentemente da temperatura e do regime de luz, com destaque para a alta porcentagem de germinação em condições de sombra (KOBORI et al., 2009). Muito rústica, se desenvolve bem tanto a pleno sol quanto a meia sombra, embora as plantas jovens necessitem de sombra parcial; adapta-se bem em ambientes perturbados e em florestas secundárias. Pode ser considerada uma espécie subtropical, tolerando tanto os trópicos como as regiões temperadas, onde suporta geadas invernais (KOBORI, 2006).

Archontophoenix cunninghamiana (H.Wendl.) H.Weldl. \& Drude, popularmente conhecida como "palmeira-australiana" ou "seafórtia", foi introduzida no Brasil para uso ornamental, mas acabou tornandose invasora de fragmentos florestais remanescentes no estado de São Paulo, Santa Catarina e Rio Grande do Sul (INSTITUTO HÓRUS DE DESENVOLVIMENTO E CONSERVAÇÃO AMBIENTAL; THE NATURE 
CONSERVANCY, 2005). Espécie originária da Austrália, é uma palmeira arborescente, tolerante a climas temperados e que se propaga apenas por sementes (BOVI, 1998). Planta monoica, possui crescimento monopodial e floresce por vários anos, com uma sucessão de inflorescências intrafoliares, com cerca de um metro de comprimento, visitadas durante o ano todo por várias espécies de abelhas sociais à procura de néctar e pólen (PIRANI; CORTOPASSI-LAURINO, 1994). A frutificação é abundante, com drupas esféricas vermelhas, de 1-2 cm de diâmetro, amplamente consumidas por aves em seu habitat original (WATERHOUSE; QUINN, 1978; ZONA; HENDERSON, 1989). Produz cerca de 1.600 sementes por quilo de frutos (INSTITUTO HÓRUS DE DESENVOLVIMENTO E CONSERVAÇÃO AMBIENTAL; THE NATURE CONSERVANCY, 2005).

Realizamos o controle químico das palmeirasaustralianas e palmeiras-leque no arboreto de cedrovermelho (Taxodium distichum (L.) Rich.) cultivado em área brejosa na década de 1960. As árvores dessa espécie têm em média $50 \mathrm{~cm}$ de diâmetro e formam dossel irregular de $30 \mathrm{~m}$ de altura. As palmeiras invasoras ocuparam o subosque desse talhão, competindo com populações nativas da palmeira-juçara (Euterpe edulis L.).

De cada população selecionamos 30 palmeiras tratamento (controle químico) e 10 testemunhas (sem controle químico). Adotamos critério de inclusão distinto entre as espécies, pois a palmeira-leque é acaule na sua fase juvenil. Assim, incluímos as palmeiras-australianas com meristema apical superior a $130 \mathrm{~cm}$ de altura do solo e as palmeiras-leque com a base da bainha foliar superior a $100 \mathrm{~cm}$ de altura do solo. Cada indivíduo do grupo controle ou tratamento recebeu uma plaqueta numerada e uma bandeirola de sinalização (com cores distintas para grupo controle e tratamento).

Utilizamos o herbicida não seletivo de ação sistêmica, do grupo químico glicina substituída, conhecido comercialmente como ROUNDUP TRANSORB R, registrado no Ministério da Agricultura, Pecuária e Abastecimento (MAPA) com o número 09306. A autorização de uso de herbicida na unidade de conservação seguiu a normativa estabelecida pelo órgão gestor da unidade, projeto número 3.321/2016, o qual registramos na Comissão Técnico Científica do Instituto Florestal. Cada litro do produto ROUNDUP TRANSORB R corresponde a $588 \mathrm{~g} / \mathrm{L}$ do sal de potássio de glifosato ou $480 \mathrm{~g} / \mathrm{L}$ do equivalente ácido de glifosato.

Realizamos o manuseio e a aplicação do herbicida com o uso de equipamento de proteção individual (EPI) (Figura 1) e em condições climáticas favoráveis (temperatura máxima de $28^{\circ} \mathrm{C}$ e umidade relativa mínima de $55 \%$, evitando-se dias chuvosos). Diluímos o produto em água limpa (sem argila, limo e matéria orgânica em suspensão) e o aplicamos na dosagem de 30\% (150 mL do produto diluído em $350 \mathrm{~mL}$ de água). A essa solução adicionamos um corante (violeta de genciana), solução inerte, para evidenciar qualquer vazamento ou respingo durante a aplicação.

Aplicamos a solução de herbicida no estipe das palmeiras por meio de furos oblíquos e direcionados para baixo. Realizamos as perfurações com auxílio de perfurador a gasolina (STIHL BT 45) acoplado a uma broca de 9,3 $\mathrm{mm}$ de diâmetro, a qual produziu orifícios com aproximadamente $1,0 \mathrm{~cm}$ de diâmetro.

A definição da dosagem da solução de herbicida por indivíduo foi baseada no estudo prévio de Bitencourt e Pivello (2013), os quais aplicaram a dosagem padronizada de $30 \mathrm{~mL}$ por indivíduo de palmeiraaustraliana. No entanto, como os autores relataram que palmeiras com diâmetro, a $130 \mathrm{~cm}$ de altura do solo, superior a $24 \mathrm{~cm}$ sobreviveram ao tratamento químico, e nem apresentaram sinais de senescência, aplicamos a dosagem de solução de herbicida de forma proporcional ao diâmetro/perímetro das palmeiras.

Desse modo, receberam dose única de $30 \mathrm{~mL}$ de solução de herbicida todas as palmeiras-australianas do grupo de tratamento selecionado com até $15 \mathrm{~cm}$ de perímetro à altura do peito (PAP) e as palmeiras-leque com diâmetro à altura do solo (DAS) até $90 \mathrm{~cm}$. Para as palmeiras com critérios superiores aos mencionados, realizamos um furo a cada $10 \mathrm{~cm}$ de perímetro/diâmetro, com a aplicação de $10 \mathrm{~mL}$ de solução de herbicida por furo. Esse acréscimo de solução baseado no perímetro/ diâmetro das palmeiras embasou-se no estudo de Abreu (2013), o qual aumentou a dosagem de herbicida 
FIGURA 1: Preparo da solução de herbicida para controle químico de palmeiras invasoras no PEAL. A - Adição de violeta genciana em 350 mL de água em frasco para nutrição enteral; B - Roundup Transorb R (glifosato); C - 150 mL de herbicida puro; $\mathrm{D}$ - Diluição do herbicida em água, com auxílio de funil.
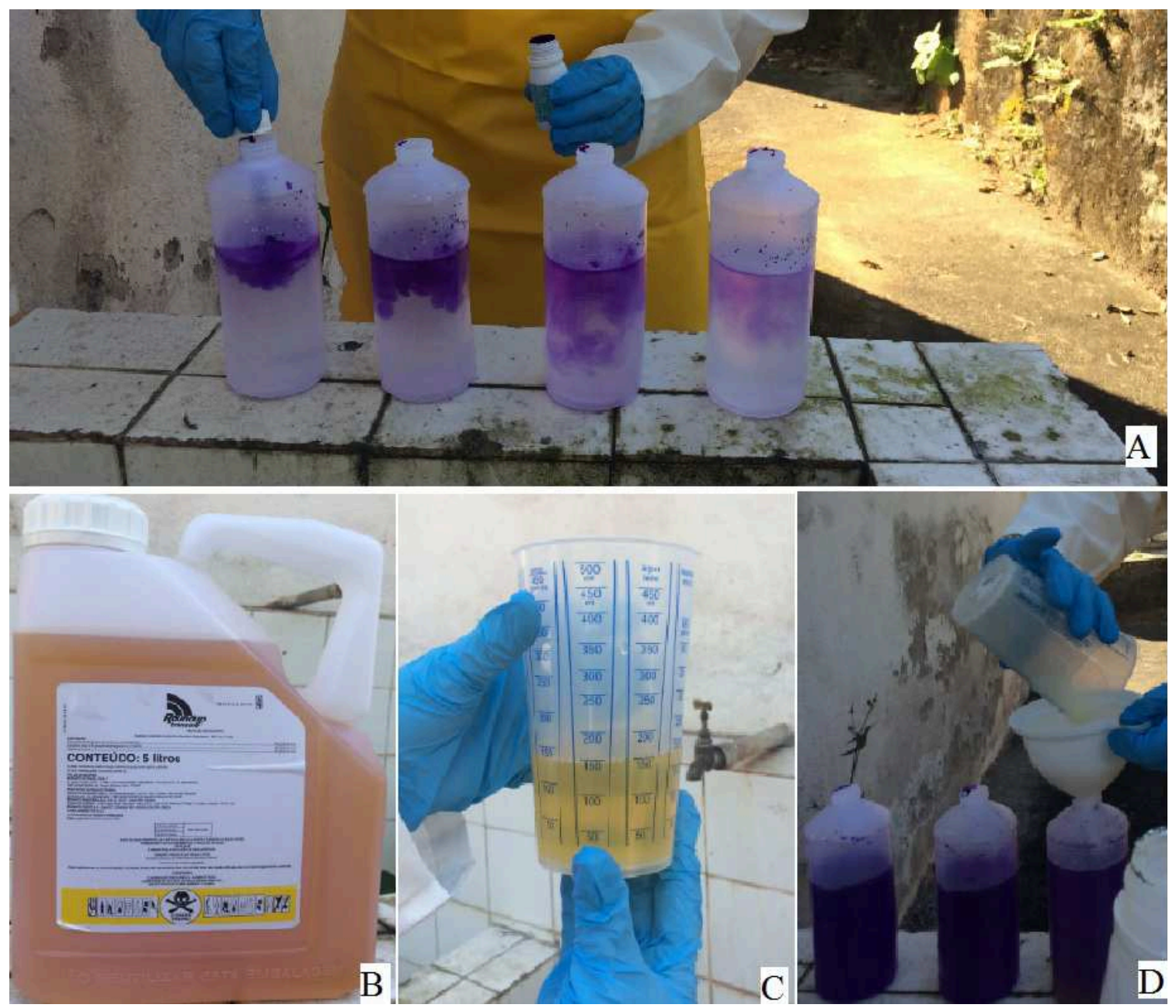

aplicado em Pinus spp. a cada $10 \mathrm{~cm}$ adicional de perímetro. Portanto, a dosagem mínima que utilizamos nas palmeiras foi de $30 \mathrm{~mL}$, enquanto a máxima foi de $100 \mathrm{~mL}$ por indivíduo. Após a aplicação da solução, preenchemos os orifícios com massa corrida, para evitar que a fauna tivesse acesso ao herbicida (Figura 2).

Anotamos o diâmetro/perímetro de cada palmeira e a dose aplicada de solução de herbicida em planilha de campo, de acordo com o número do indivíduo na plaqueta de identificação. Registramos os estados fitossanitários de cada indivíduo com câmera fotográfica e os acompanhamos semanalmente, a partir de sete dias após a aplicação da solução de herbicida nas palmeiras. Adotamos como protocolo de acompanhamento do tratamento químico três estados fitossanitários, adaptados de Moura (2011): normal (palmeira não reagiu ao tratamento); senescente (palmeira com sinais de intoxicação nas folhas e decrepitude devido ao tratamento) e morta (palmeira seca, com queda da gema apical/palmito).

Representamos os sintomas de senescência em cada população em gráficos de área empilhada a 100\%, os quais apresentam a tendência da percentagem com que cada sintoma contribuiu até a morte das palmeiras ao longo do tempo. Construímos os gráficos utilizando a matriz de número de palmeiras agrupadas por categoria de sintomas a cada semana de observação, por meio do programa Microsoft Office Excel versão 2007. 
FIGURA 2: Aplicação da solução do herbicida (glifosato 30\%) para controle químico de palmeiras invasoras no PEAL. A - Utilização de perfurador para abertura de orifícios na palmeira-australiana; B - Utilização de perfurador para abertura de orifícios na palmeira-leque; C - Sucção da solução de herbicida com seringa plástica para aplicação; D - Introdução de solução de herbicida em palmeira-leque; E - Orifício tampado com massa corrida na palmeira-leque e F - Orifícios tampados com massa corrida na palmeira-australiana (setas).
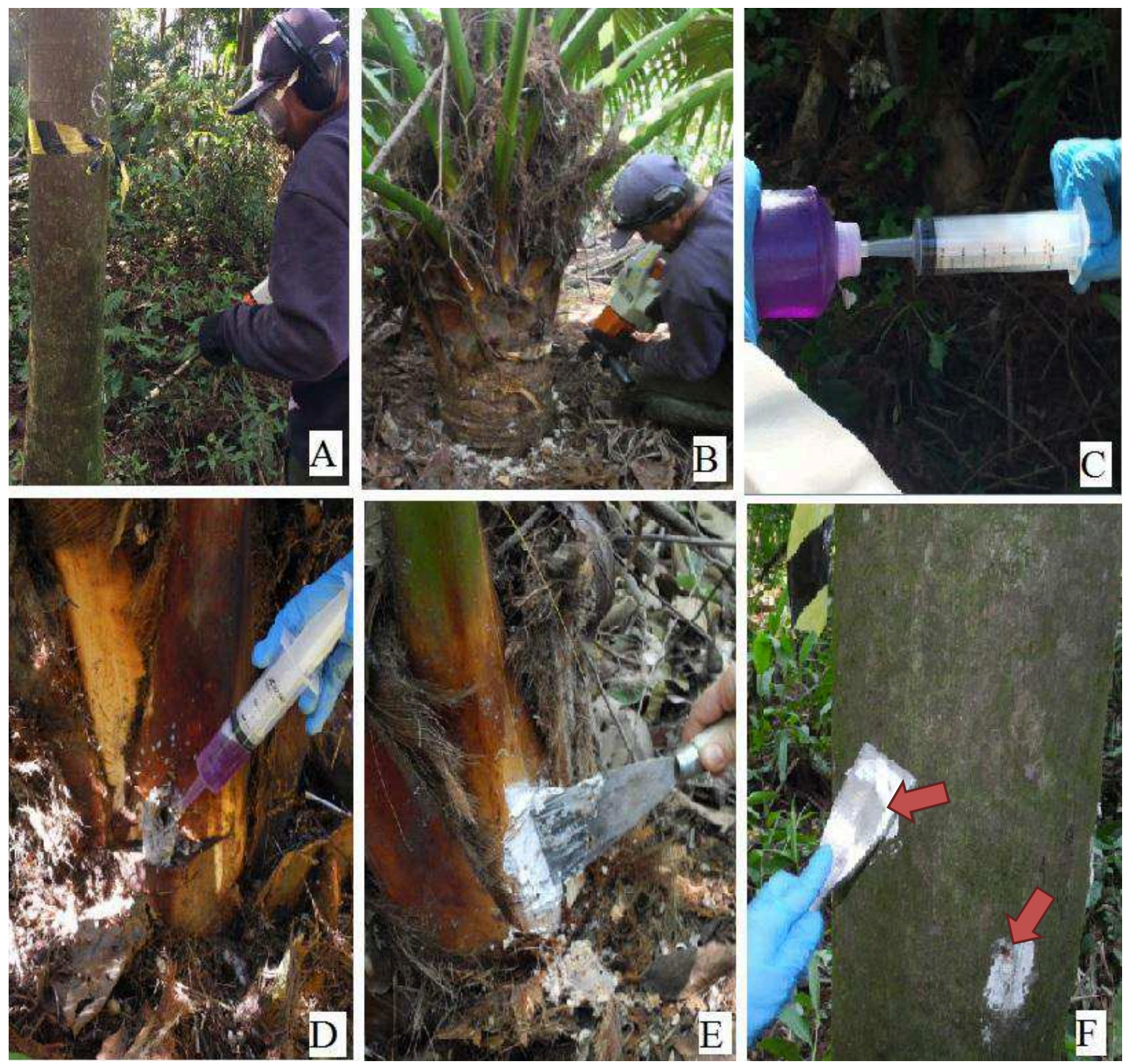

Expressamos a relação entre o perímetro/diâmetro das palmeiras e os estados fitossanitários observados por meio de gráfico de diagrama pontual (dot plot), conforme modelo apresentado por Moura (2011), elaborado com o uso do programa Microsoft Office Excel versão 2007. Consideramos as respostas dos indivíduos das duas populações, desde o início da senescência até a morte das palmeiras, as quais agrupamos por número de semanas após o tratamento (1, 9, 18 e 29 semanas).
Acrescentamos aos gráficos, com o uso do programa Microsoft Office PowerPoint versão 2007, as doses de solução de herbicida aplicadas conforme o diâmetro/ perímetro das palmeiras.

\section{Resultados}

Para nenhuma das populações foi necessária nova aplicação de herbicida (repasse) e as palmeiras controle 
mantiveram-se saudáveis durante todo o período do experimento. Palmeiras-leque e palmeiras-australianas apresentaram sintomas de senescência a partir da semana seguinte à aplicação do herbicida. Entretanto, os sintomas observados em cada uma das populações foram distintos (Figuras 3 e 4). As palmeiras-leque apresentaram sintomas de senescência na seguinte progressão: folhas amarelas, folhas secas, dessecamento da gema apical e desmanche do estipe, e a palmeira foi considerada morta após a secagem de todas as folhas e da gema apical (Figura 3). As palmeiras-australianas apresentaram como sintomas de senescência: folhas amarelas, folhas secas, bainha tombada junto ao estipe, estipe tombado, presença de larva de cupim, exsudato no estipe, e a morte para tais indivíduos foi determinada a partir da queda do palmito (Figura 4).

Na palmeira-leque os sintomas de senescência surgiram de modo gradual e desuniforme na população alvo de tratamento (Figura 5). Indivíduos já apresentavam folhas secas na primeira semana, enquanto outros mantinham as folhas amareladas. O dessecamento da gema apical iniciou na terceira semana e os primeiros indivíduos mortos (desmanche do estipe) foram registrados a partir da quinta semana após o tratamento.

Comparada à palmeira-leque, a palmeiraaustraliana apresentou maior número de sintomas e período de senescência (Figura 6). Na primeira semana,

FIGURA 3: Sintomas de senescência observados após a aplicação da solução do herbicida (glifosato 30\%) para controle químico de palmeira-leque no PEAL. A - folhas amarelas (segunda semana); B - folhas amarelas (terceira semana); C - folhas secas (quarta semana); D - folhas secas (quinta semana); E - folhas secas e desmanche do estipe (sexta semana); F - Folhas secas e desmanche do estipe (sétima semana).
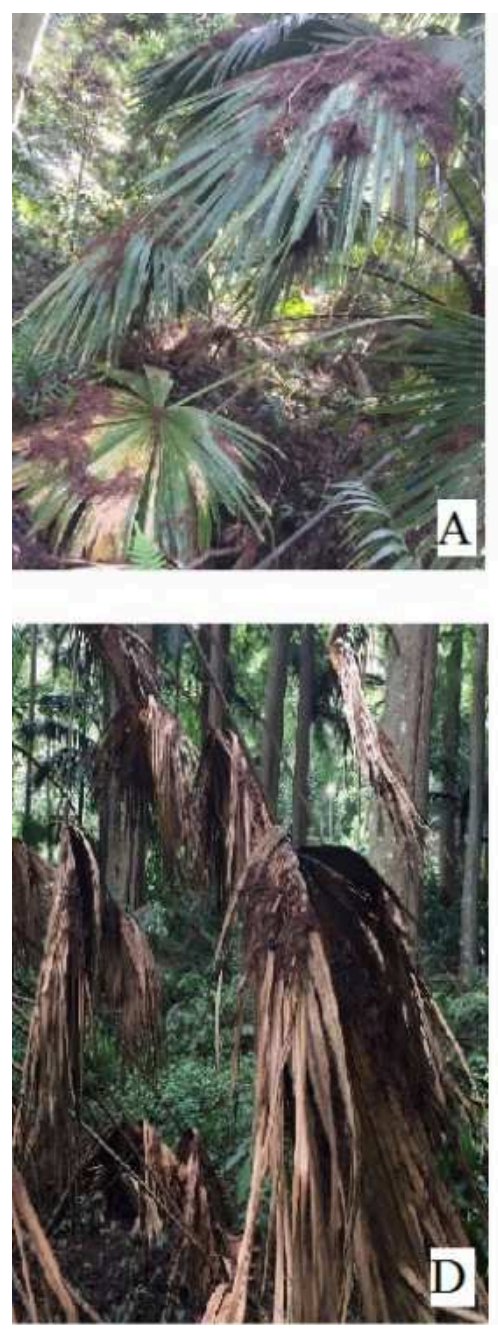
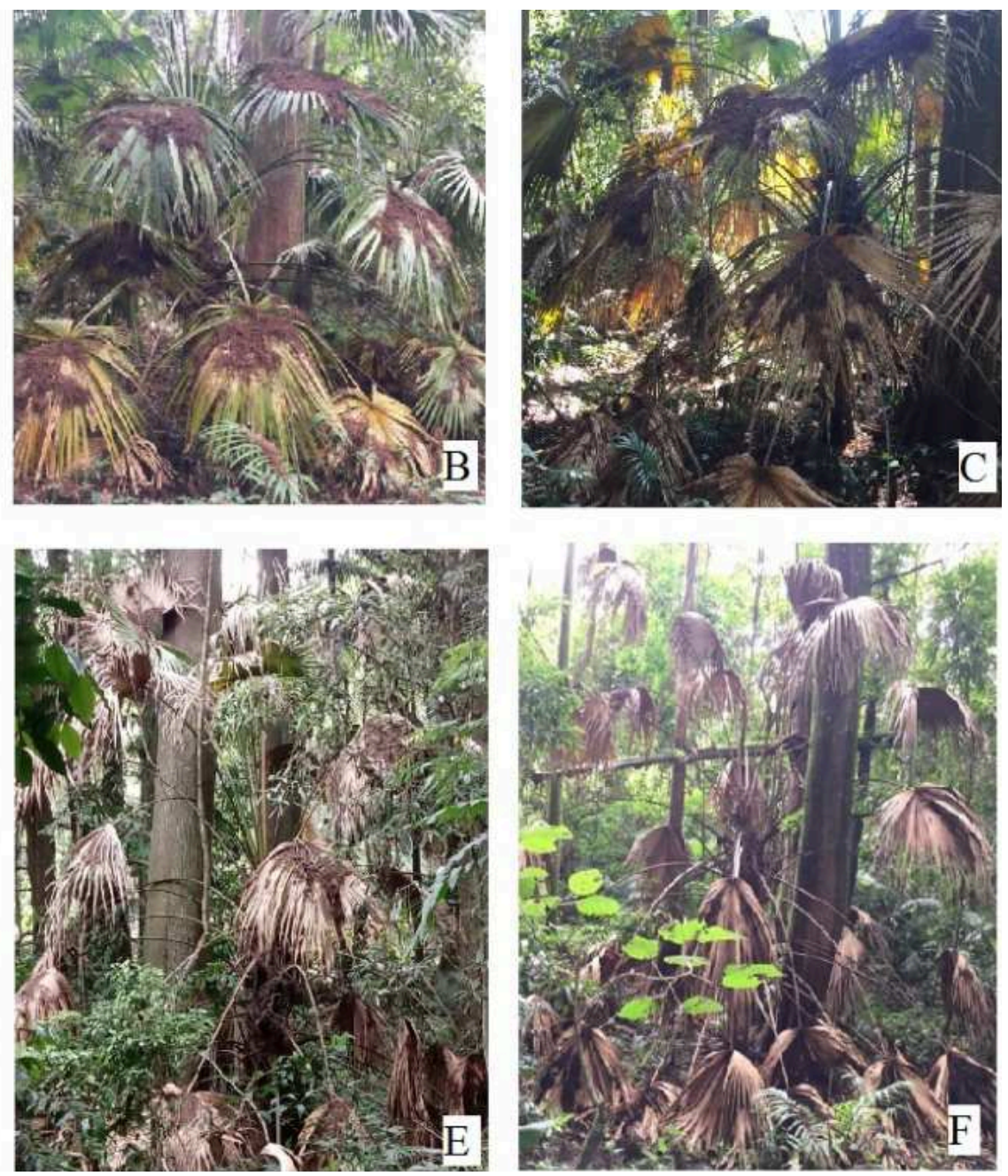
FIGURA 4: Sintomas de senescência observados após a aplicação da solução do herbicida (glifosato 30\%) para controle químico de palmeira-australiana no PEAL. A - dobra da bainha foliar (terceira semana); B - aumento de folhas secas (quinta semana); $\mathrm{C}$ - rachadura no estipe (sexta semana); D - queda de palmito (décima primeira semana); E - exsudato no estipe (décima segunda semana) e F - larvas de cupim (décima segunda semana).
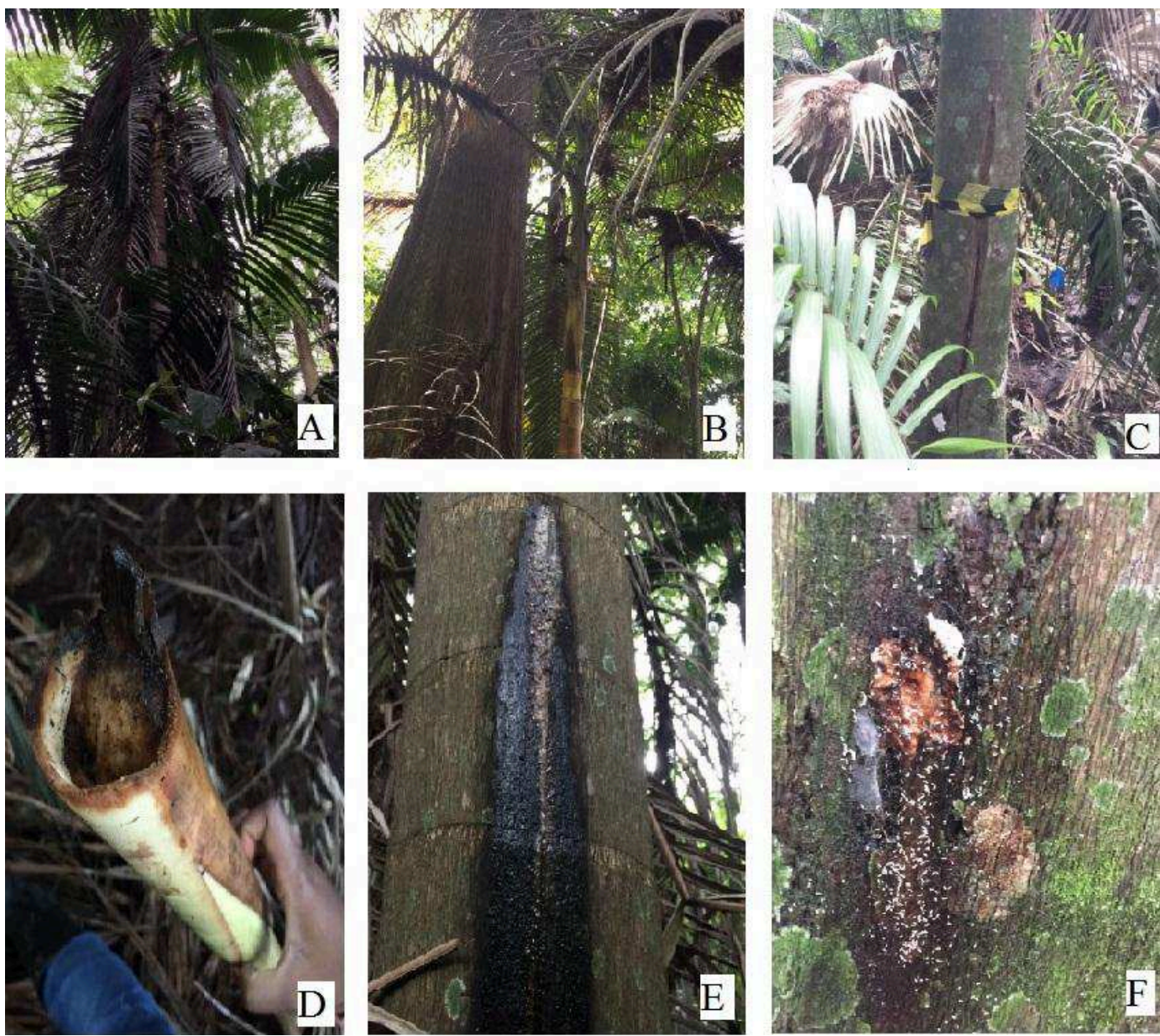

FIGURA 5: Acompanhamento semanal dos sintomas da palmeira-leque (Livistona chinensis) após aplicação de controle químico. Sintomas: FA - folhas amarelas, FS - folhas secas, GA - seca da gema apical, DE - desmanche do estipe. Sintomas ilustrados na Figura 4.

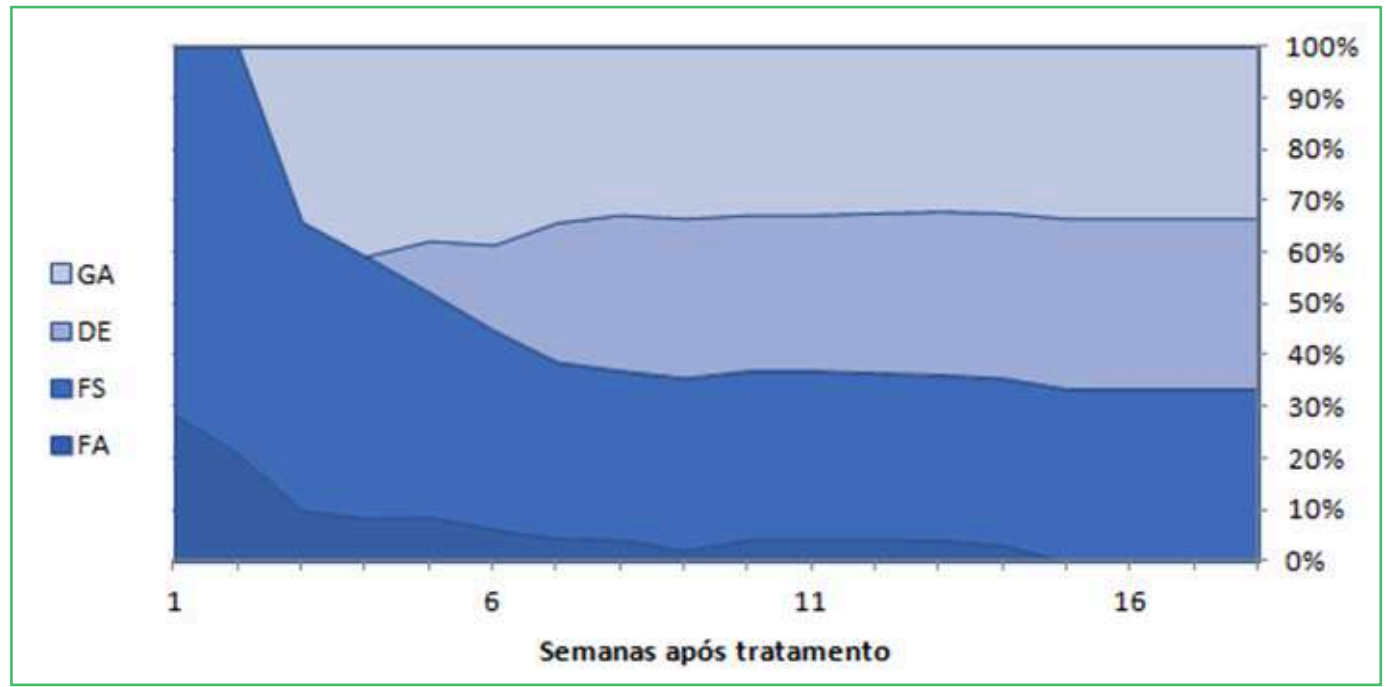


FIGURA 6: Acompanhamento semanal dos sintomas da palmeira-australiana (Archontophoenix cunninghamiana) após aplicação de controle químico. Sintomas: FA - folhas amarelas, FS - folhas secas, DB - dobra da bainha, RE - rachaduras no estipe, EE exsudato no estipe, LC - larvas de cupim, QP - queda do palmito. Sintomas ilustrados na Figura 5.

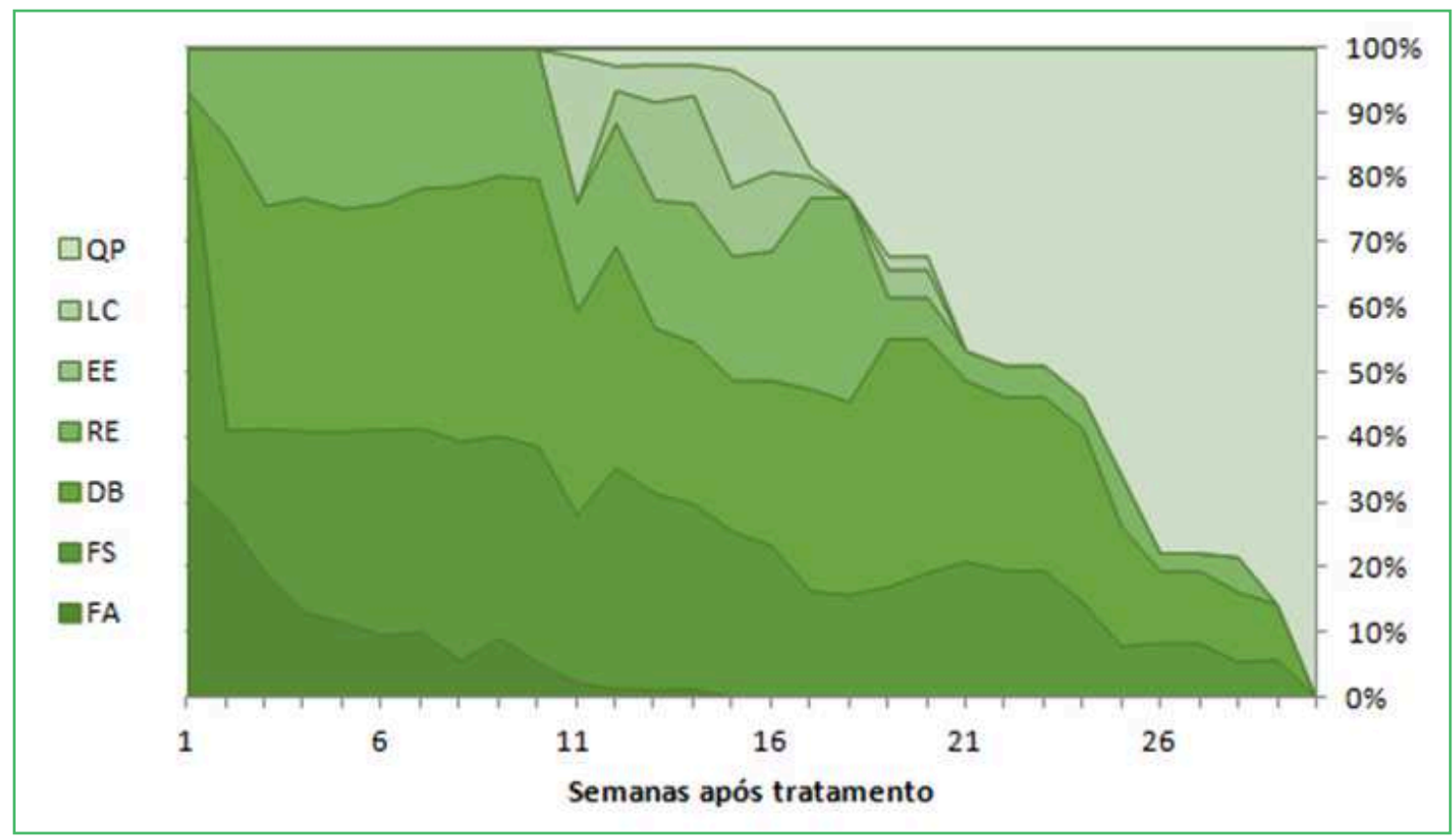

mais da metade já apresentava folhas secas, enquanto o restante começava a apresentar folhas amarelas. Nem todas as palmeiras-australianas apresentaram folhas amarelas, mas todas exibiram folhas secas e, na maioria dos indivíduos, bainha tombada junto ao estipe a partir da segunda semana. Concomitantemente aos sintomas anteriores, alguns indivíduos apresentaram rachaduras, larvas de cupim e exsudato no estipe.

O controle químico foi eficiente para controle de palmeiras-leque, pois $100 \%$ dos indivíduos morreram entre 50-60 dias após a aplicação (Figura 7). A técnica de adequar a dosagem do herbicida ao porte das palmeiras se mostrou eficiente, pois palmeiras de grande e pequeno porte morreram no mesmo período.

Assim como para as palmeiras-leque, o método de adequação dos herbicidas ao porte das palmeirasaustralianas foi eficiente, mas o período até a mortalidade foi superior (203 dias ou 29 semanas). Observamos o início da mortalidade dos indivíduos entre 80-130 dias e a maior parte das palmeiras morreu 110-130 dias após a aplicação do herbicida (Figura 8). 
FIGURA 7: Doses de solução de herbicida aplicados conforme o diâmetro à altura do solo (DAS) de indivíduos de palmeira-leque (Livistona chinensis) e estados de senescência após semanas de aplicação. Estados de senescência: N - normal; $\mathrm{S}$ - senescente; M morta. Cada círculo representa o estado de senescência de uma palmeira em cada período (1,9 e 18 semanas após a aplicação da solução de herbicida).

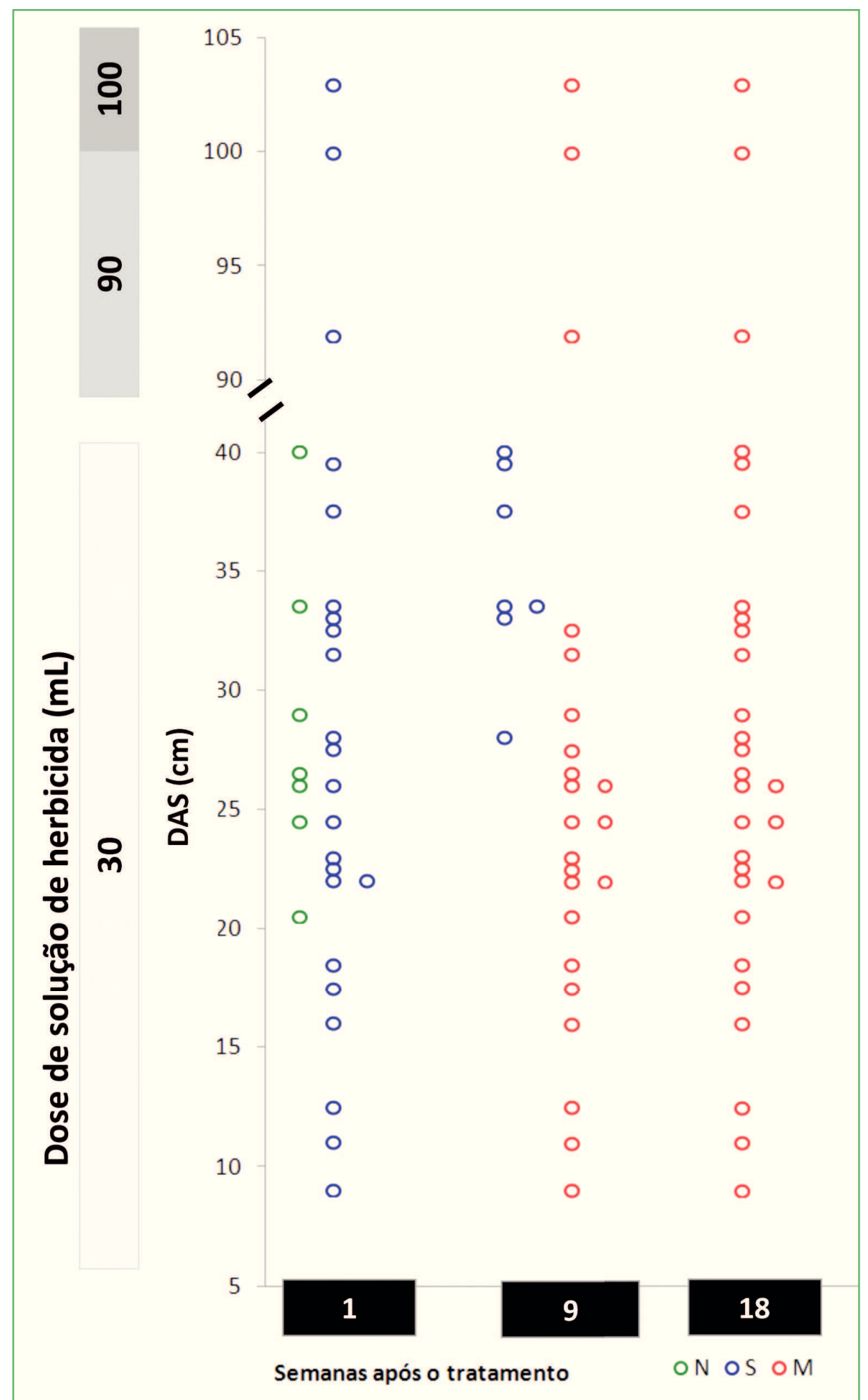


FIGURA 8: Doses de solução de herbicida aplicados conforme o perímetro à altura do solo (PAS) de indivíduos de palmeira-australiana (Archontophoenix cunninghamiana) e estados de senescência após semanas de aplicação. Estados de senescência: $\mathrm{N}$ - normal; $\mathrm{S}$ - senescente; $\mathrm{M}$ - morta. Cada círculo representa o estado de senescência de uma palmeira em cada período $(1,9,18$ e 29 semanas após a aplicação da solução de herbicida).

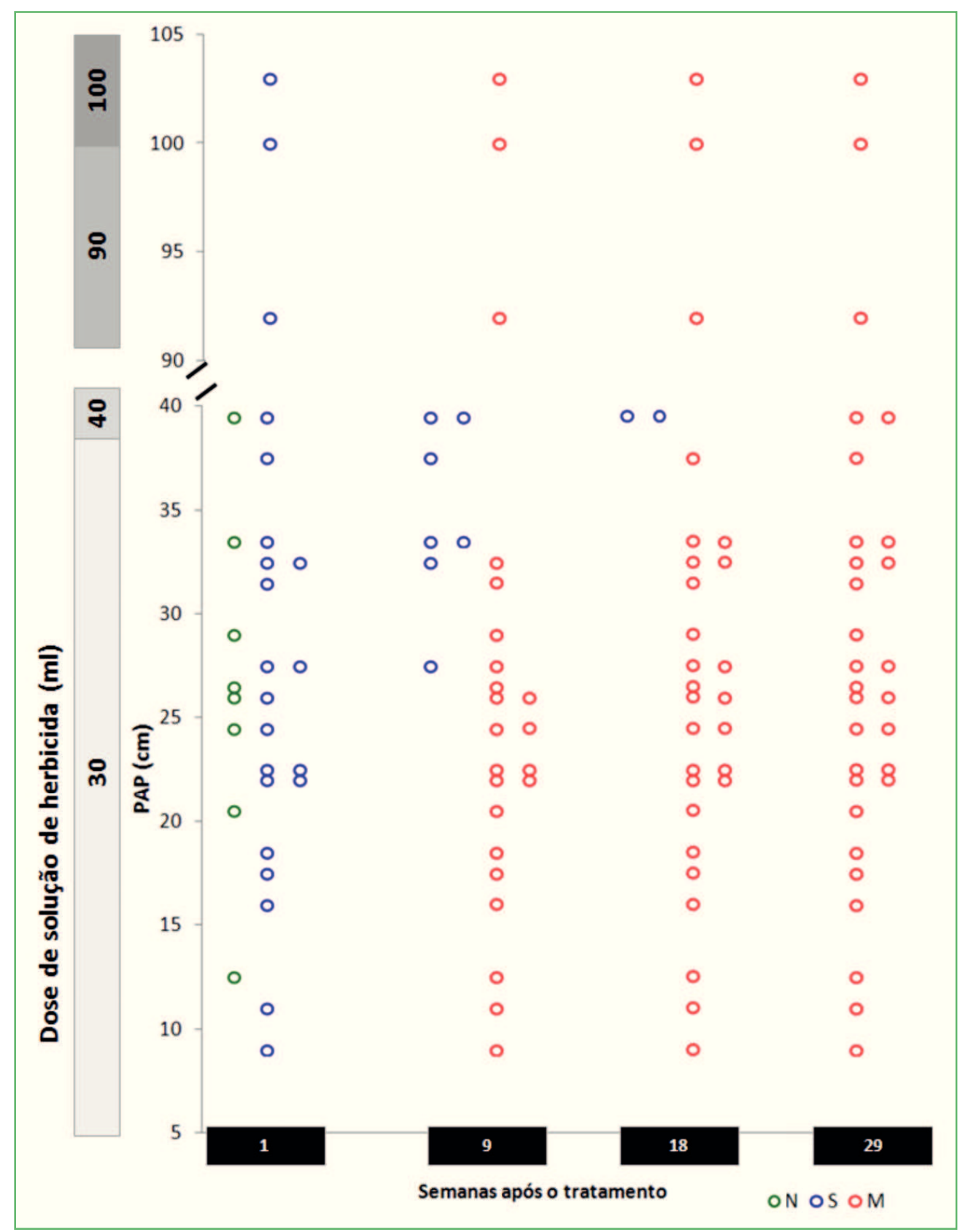

\section{Discussão}

O controle químico foi eficaz para todos os indivíduos de palmeiras-australianas e palmeirasleques testados, pois culminou na morte de todas as palmeiras submetidas ao tratamento. A eficácia do método está apoiada na correta escolha do princípio ativo glifosato, no preparo da solução a $30 \%$ e na aplicação de solução diretamente no estipe das palmeiras, em dosagem proporcional ao perímetro/ diâmetro dos indivíduos, pois o repasse para aplicação do produto não foi necessário. 
Há poucos estudos sobre manejo químico de plantas de porte arbóreo, o que torna este estudo mais uma importante contribuição científica para embasar ações práticas de manejo. As informações disponíveis sobre técnicas de controle dessas invasoras em ecossistemas tropicais foram compiladas e disponibilizadas em Barros (2018). De acordo com a autora, somente Abreu (2013) utilizou o herbicida glifosato para o controle de Pinus elliottii, com $2 \mathrm{~mL}$ do produto puro injetado a cada 10 $\mathrm{cm}$ de perímetro, também com taxa de mortalidade alta. Outros herbicidas utilizados para controle de invasoras de porte arbóreo incluem os princípios ativos triclopir (MOURA, 2011; DECHOUM; ZILLER, 2013) e a mistura de ácido diclorofenóxiacético (2,4 - D) + picloram (GONÇALVES et al., 2015). As técnicas aplicadas foram a injeção de herbicida, anelamento + aplicação de herbicida, corte na base do tronco + aplicação de herbicida ou a aspersão de herbicida na base do tronco.

Apesar da eficácia, o controle químico em áreas naturais sempre foi polêmico, pelo risco de contaminação ambiental. Considerando-se a classificação ambiental informada na bula dos produtos, os herbicidas triclopir e picloram são considerados muito perigosos (classe II - faixa amarela), enquanto glifosato e 2,4-D são considerados perigosos (classe III - faixa cinza). No entanto, entre os herbicidas citados, triclopir e a mistura $2,4 \mathrm{D}+$ picloram são extremamente tóxicos para a saúde humana (classe toxicológica I - faixa vermelha), enquanto glifosato é considerado pouco tóxico (classe toxicológica IV - faixa verde). Nesse contexto, a opção por glifosato concilia o menor risco de contaminação ambiental e a menor toxicidade à saúde humana entre os herbicidas já testados para controle de plantas invasoras de porte arbóreo. Glifosato é amplamente utilizado no cultivo de frutas, culturas de arroz, cana-de-açúcar, entre outras (AMARANTE JUNIOR et al., 2002). A sua eficácia se deve à capacidade enzimática inibitória, que causa redução de aminoácidos aromáticos das plantas desregulando o metabolismo, a ponto de comprometer sua sobrevivência (LELES; RESENDE, 2017).

Certamente o controle mecânico apresenta maior segurança tanto para o ambiente quanto para o aplicador, sendo altamente recomendável para o controle de palmeiras jovens ou de pequeno porte. No entanto, questões financeiras e operacionais devem ser consideradas no processo de decisão, e o custo de mão-de-obra no controle químico é considerado baixo comparado ao controle mecânico (LELES; RESENDE, 2017). No âmbito das técnicas de manejo adaptativo, a severidade do distúrbio causado pela técnica empregada no ecossistema a ser restaurado é o principal critério a ser considerado (DURIGAN et al., 2013).

Nesse cenário, uma das vantagens do controle químico é a "morte em pé" de palmeiras invasoras de grande porte. Bitencourt e Pivello (2013) demonstraram que o corte na base do estipe das palmeiras de elevado diâmetro pode danificar as plantas ciófilas já estabelecidas no subosque e causar a abertura de grandes clareiras, favorecendo o recrutamento de espécies heliófitas, entre as quais as próprias invasoras presentes no banco de sementes (TABARELLI; MANTOVANI, 1998). Com a "morte em pé", a vegetação do entorno é poupada e a decomposição lenta torna desnecessária a retirada de resíduos do corte, evitando assim o arraste de material de grande porte, o que poderia causar danos ao subosque, ao estrato regenerante, alterar a serapilheira e prejudicar a fauna associada (CARNEIRO, 2002).

Com relação ao risco de contaminação ambiental, um fator importante é a deriva de herbicida, que pode ocorrer durante o processo de aplicação do produto, diminuindo a eficácia da aplicação e comprometendo a fauna e a flora nativas, a qualidade da água local e a saúde do aplicador (LEITE; SERRA, 2013). Nessa questão é importante enfatizar o método que empregamos para a aplicação do glifosato, o qual foi injetado diretamente no estipe das palmeiras. Como cada orifício do estipe foi imediatamente selado após a aplicação, as possibilidades de acesso da fauna ao produto também foram reduzidas, evitando-se o envenenamento. Requer atenção o cuidado no transporte da solução durante a etapa de campo, a fim de evitar respingos e vazamentos no processo de reabastecimento da seringa. Nesse caso, o emprego do corante para visualização da solução e o transporte em frascos para nutrição enteral com acoplamento equivalente ao diâmetro do bico da seringa minimizam o risco de acidentes. 
Outro quesito que influi no risco de contaminação ambiental é o volume do herbicida aplicado. Volume alto, médio, baixo, muito baixo e ultrabaixo são categorias utilizadas para descrever a quantidade de líquido utilizado para aplicar um herbicida (CHAIM, 2004). Um volume inferior a $5 \mathrm{~L} /$ ha é considerado ultrabaixo, e no experimento realizado aplicamos $2.300 \mathrm{~mL}$ de solução de herbicida para a palmeira-australiana e $1.100 \mathrm{~mL}$ para a palmeira-leque em área superior a 1 ha. A dose por indivíduo não ultrapassou $100 \mathrm{~mL}$ e aparentemente não houve exsudação do produto pelas raízes das plantas alvo do tratamento, pois aquelas ao redor permaneceram vivas e sem alterações aparentes.

Herbicidas à base de glifosato são muito utilizados no controle de plantas herbáceas, justamente por não deixarem resíduos nem serem móveis no solo, pois ficam adsorvidos às partículas minerais (BUSSAN; DYER, 1999; XACT INFORMATION, 2005). Testes comprovaram que a injeção de solução desse herbicida a 30\% no estipe da palmeira-australiana não resultou em contaminação do solo (BITENCOURT; PIVELLO, 2013). Vale destacar que não registramos nenhum animal morto na área experimental e que a presença de cupins em uma das fases finais de senescência da palmeira-australiana é um bom indicador de que os processos orgânicos de decomposição foram estabelecidos.

Em síntese, o método testado foi eficaz para o controle das palmeiras-australianas e palmeiras-leque nas condições ambientais deste estudo e pode ser uma boa alternativa em termos operacionais, econômicos e ecológicos para o manejo de palmeiras invasoras de grande porte. Para as palmeiras de porte inferior ao testado neste estudo sugerimos métodos mecânicos. No manejo devem ser priorizadas as palmeiras adultas, a fim de eliminar as matrizes responsáveis pela pressão de propágulos. Após o controle desses indivíduos prioritários, é necessário realizar o controle dos indivíduos jovens, até que a população de exóticas invasoras não comprometa o estabelecimento das plantas nativas e a trajetória sucessional ascendente das áreas restauradas.

\section{Agradecimentos}

À professora Vania Regina Pivello e a Augusto C. D. Bitencourt, por compartilhar experiências e informações do projeto de manejo palmeira-australiana na Reserva Florestal da CUASO. À Flaviana Maluf de Souza e Giselda Durigan pela revisão do abstract e sugestões ao texto. À gestora do Parque Estadual Alberto Löfgren, Roselaine Barros Machado. Aos funcionários da equipe terceirizada de manutenção do PEAL Olenilson Santiago e a Valmir Anderson Ribeiro Sales pelo auxílio no manejo. À Sandra Monteiro Borges Florsheim, pelo empréstimo do perfurador, e ao Hugo da Fonseca Alves Pereira pelo treinamento na operação do equipamento. Ao $\mathrm{CNPq}$, pela bolsa de iniciação científica da segunda autora.

\section{Referências}

ABREU, R. C. R. Ecologia e controle da invasão de Pinus elliottii no campo cerrado. 2013. 94 f. Tese (Doutorado em Ciências da Engenharia Ambiental) - Universidade de São Paulo, São Carlos. 2013.

AMARANTE JUNIOR, O. P.; SANTOS, T. C. R.; BRITO, N. M. B.; RIBEIRO, M. L. Glifosato: propriedades, toxidade, usos e legislação. Química Nova, São Paulo, v. 24, n. 4, p. 589-593, 2002. ARZOLLA, F. A. R. D. P. (Coord.). Meio Biótico. In: SÃO PAULO. Governo do Estado. Secretaria do Meio Ambiente. Instituto Florestal. Plano de Manejo do Parque Estadual da Cantareira. São Paulo: Instituto Florestal, 2009. p. 109-144.

ARZOLLA, F. A. R. D. P. (Coord.). Meio Biótico. In: SÃO PAULO. Governo do Estado. Secretaria do Meio Ambiente. Instituto Florestal. Parque Estadual Alberto Löfgren - Plano de Manejo. São Paulo: Instituto Florestal, 2012. p. 111-144.

AZEVEDO, C. (Coord.). Estratégia paulista sobre espécies exóticas invasoras. Relatório do Grupo de Trabalho da Resolução SMA 33/2009. Vol. 1 e 2. São Paulo: SMA/SP - CBRN/DPB/CPA, 2009.

BARROS, A. B. S. C. Bibliographical review - Invasive species. 2018. Figshare. doi: <https://doi.org/10.6084/m9.figshare.6127331. $\mathrm{v} 1>$.

BITENCOURT, A. C. C. Análise crítica do manejo da palmeira invasora Archontophoenix cunninghamiana H. Wendl. \& Drude na reserva florestal da Universidade de São Paulo, SP. São Paulo: Universidade de São Paulo, 2013. 50 p. (Relatório Final)

BITENCOURT, A. C. C.; PIVELLO, V. Teste de herbicidas para o manejo da palmeira invasora Archontophoenix cunninghamiana na reserva florestal da Cidade Universitária (USP - São Paulo). In: CONGRESSO DE ECOLOGIA DO BRASIL, XI, 2013, Porto Seguro. Anais... Porto Seguro: Sociedade de Ecologia do Brasil, 2013. Versão eletrônica. 
BOVI, M. L. A. O cultivo da palmeira real australiana visando à produção de palmito. Campinas: IAC, 1998. 26 p. (Boletim Técnico, n. 15)

BUSSAN, A. J.; DYER, W. E. Herbicides and rangeland. In: SHELEY, R. L.; PETROFF, J. K. (Ed.). Biology and management of noxious rangeland weeds. Corvallis: Oregon State University Press, 1999. p. 116-132.

CAMPAGNOLI, M. L; ANTUNES, A. Z. Densidade de palmeiras exóticas invasoras influenciando a avifauna de sub-bosque na Mata Atlântica do Sudeste do Brasil. Neotropical Biology and Conservation, São Leopoldo, v. 12, n. 1, p. 37-47, 2017.

CARNEIRO, P. H. M. Caracterização florística, estrutural e da dinâmica da regeneração de espécies nativas em um povoamento comercial de Eucalyptus grandis em Itatinga, SP. 2002. $131 \mathrm{f}$. Dissertação (Mestrado em Ciências Florestais) - Escola Superior de Agricultura Luiz de Queiroz, Piracicaba. 2002.

CATHARINO, E. L. M.; ARAGAKI, S. A. A vegetação do município de São Paulo: de Piratininga à metrópole paulistana. In: MALAGOLI, L. R.; BAJESTEIRO, F. B.; WHATELY, M. (Org.). Além do concreto: contribuições para a proteção da biodiversidade paulistana. São Paulo: Instituto Socioambiental, 2008. p. 54-89.

CHAIM, A. Tecnologia de aplicação de agrotóxicos: fatores que afetam a eficiência e o impacto ambiental. In: SILVA, C. M. M. S.; FAY, E. F. (Ed.). Agrotóxicos \& Ambiente. Brasília: Embrapa, 2004. p. 289-317.

CHRISTIANINI, A. Fecundidade, dispersão e predação de sementes de Archontophoenix cunninghamiana H. Wendl. \& Drude, uma palmeira invasora da Mata Atlântica. Revista Brasileira de Botânica, São Paulo, v. 29, p. 587-594, 2006.

COCESP - COORDENADORIA DO CAMPUS DA CAPITAL DO ESTADO DE SÃO PAULO. Projeto de recuperação da mata ciliar em nascente, córrego, lago e canal de drenagem no campus capital da USP - Memorial Descritivo. Disponível em $<$ http://www.pha.poli.usp.br/LeArq.aspx?id_arq=5576>. Acesso em: 11 nov. 2018.

CONDÉ, T. M.; SILVA, F.; SOUZA, A. L.; LEITE, H. G.; GARCIA, E. A.; COSTA, W. S., CHAVES, A. S.; LOPES, P. F. Exotic palms threatens native palms: a risk to plant biodiversity of Atlantic Forest. Revista Árvore, Viçosa, v. 42, n. 2, 2018.

DAVIES, K. W.; SHELEY, R. L. Promoting native vegetation and diversity in exotic annual grass infestations. Restoration Ecology, Crawley, v. 9, n. 2, p. 159-165, 2011.

DECHOUM, M. S. ZILLER, S. R. Métodos para controle de plantas exóticas invasoras. Biotemas, Florianópolis, v. 26, n. 1, p. 69-77, 2013.

DISLICH, R.; KISSER, N.; PIVELLO, V. R.; A invasão de um fragmento florestal em São Paulo (SP) pela palmeira australiana Archontophoenix cunninghamiana H. Wendl. \& Drude. Revista Brasileira de Botânica, São Paulo, v. 25, n. 1, p. 55-64, 2002.

DURIGAN, G.; IVANAUSKAS, N. M.; ZAKIA, M. J. B.; ABREU, R. C. R. Control of invasive plants: ecological and socioeconomic criteria for the decision making process. Natureza \& Conservação, Curitiba, v. 11, n. 1, p. 23-30, 2013.

DURIGAN, G.; RAMOS, V. S. Apresentação. In: DURIGAN, G.; RAMOS, V. S. (Ed.). Manejo adaptativo: primeiras experiências na restauração de ecossistemas. São Paulo: Páginas \& Letras Editora e Gráfica, 2013. p. IX-X.
FONSECA, F. Y.; ANTUNES, A. Z. Frugivoria e predação de sementes por aves no Parque Estadual Alberto Löfgren, São Paulo, SP. Revista do Instituto Florestal, São Paulo, v. 19, p. 81-91, 2007. GONÇALVES, G. S.; ANDRADE, L. A.; XAVIER, K. R. F.; SILVA, J. F. Métodos de controle de Prosopis juliflora (Sw.) DC. (Fabaceae) em áreas invadidas no semiárido do Brasil. Revista Ciência Florestal, Santa Maria, v. 25, n. 3, p. 645-653, 2015.

INSTITUTO HÓRUS DE DESENVOLVIMENTO E CONSERVAÇÃO AMBIENTAL; THE NATURE CONSERVANCY. Archontophoenix cunninghamiana. 2005. Disponível em: $<\mathrm{http}$ :// www.institutohorus.org.br/download/fichas/Archontophoenix cunninghamiana.htm>. Acesso em: 6 jan. 2011.

KOBORI, N. N. Germinação de sementes de Livistona chinensis (Jack.) R. Br. ex. Mart. (Arecaceae). 2006. 49 f. Dissertação (Mestrado em Agronomia) - Universidade Estadual Paulista "Julio de Mesquita Filho", Jaboticabal. 2006.

KOBORI, N. N.; PIVETTA, K. F. L.; DEMATTÊ, M. E. S. P.; SILVA, B. M. S.; LUZ, P. B.; PIMENTA, R. S. Efeito da temperatura e do regime de luz na germinação de sementes de palmeira-lequeda-China (Livistona chinensis (Jack.) R. Br. ex. Mart.). Revista Brasileira de Horticultura Ornamental, Campinas, v. 15, n. 1, p. 29-36, 2009.

LEITE, M. F.; SERRA, J. C. V. Avaliação dos impactos ambientais na aplicação dos agrotóxicos. Ambiência, Guarapuava, v. 9, n. 3, p. 675-682, 2013.

LELES, P. S. S.; RESENDE, A. S. (Ed.). Controle de plantas daninhas em restauração florestal. Brasília: Embrapa, 2017. 107 p.

LIEBSCH, D.; MARQUES, C. M.; GOLDENBERG, R. How long does the Atlantic Rain Forest take to recover after a disturbance? Changes in species composition and ecological features during secondary succession, Biological Conservation, Boston, v. 141, p. 1717-1725, 2008.

LOCKWOOD, J. L.; HOOPES, M. F.; MARCHETTI, M. P. Invasion ecology. Hoboken: Blackwell Publishing, 2007, 304 p.

LORENZI, H.; MEDEIROS-COSTA, J. T.; CERQUEIRA, L. S. C.; BEHR, N. von (Coord.). Palmeiras no Brasil: nativas e exóticas. Nova Odessa: Editora Plantarum, 1996. 303 p.

MANFRA, R.; IVANAUSKAS N. M. Inventário dos indivíduos de Archontophoenix cunninghamiana (H.Wendl.) H.Wendl. e Drude no Parque Estadual Alberto Löfgren, São PauloSP. 2016. São Paulo: Instituto Florestal, 2016. (Relatório final $\mathrm{PIBIC/IF)}$

MATOS, D. S. M.; PIVELLO, V. O impacto das plantas invasoras nos recursos naturais de ambientes terrestres: alguns casos brasileiros. Ciência e Cultura, São Paulo, v. 61, n. 27, p. 27-30, 2009.

MEEROW, A. W. Betrocks guide to landscape palms. Cooper City: Betrocks Information Systems, 1991. 153 p.

MOURA, C. J. R. Estrutura populacional e avaliação de métodos de controle da espécie exótica invasora Artocarpus heterophyllus Lamk. (Moraceae) no Parque Estadual da Ilha Grande, Angra dos Reis, RJ. 2011. 70 f. Dissertação (Mestrado em Ecologia e Evolução) - Universidade Estadual do Rio de Janeiro, Rio de Janeiro. 2011.

NISHIDA, S. M.; NAYDE, S. S.; PAGNIN, D. Plantas que atraem aves e outros bichos. São Paulo: Cultura Acadêmica, 2014. 95 p. 
ONOFRE, F. F. Restauração da Mata Atlântica em antigas unidades de produção florestal com Eucalyptus saligna Smith. no Parque das Neblinas, Bertioga, SP. 2009. 120 f. Dissertação (Mestrado em Recursos Florestais) - Escola Superior de Agricultura Luiz de Queiroz, Piracicaba. 2009.

PETENON, D. 1. Plantas invasoras nos trópicos: esperando a atenção mundial? 2. Abundância de sementes da palmeira invasora Archontophoenix cf. cunninghamiana na chuva e banco de sementes em um fragmento florestal em São Paulo, SP. 2006. 118 f. Dissertação (Mestrado em Ecologia) - Universidade de São Paulo, São Paulo. 2006.

PETRI, L.; ARAGAKI, S.; GOMES, E. P. C. Management priorities for exotic plants in an urban Atlantic Forest reserve. Acta Botanica Brasilica, Belo Horizonte, v. 32, p. 1-31, 2018.

PIRANI, J. R.; CORTOPASSI-LAURINO, M. Flores e abelhas em São Paulo. 2. ed. São Paulo: Editora da Universidade de São Paulo, 1994. 192 p.

PIVELLO, V. R.; PECCININI, A. A. A vegetação do PEFI. In: BICUDO, C. E. M.; FORTI, M. C.; BICUDO, D. C. (Org.). Parque Estadual das Fontes do Ipiranga: uma reserva Biológica na cidade de São Paulo. São Paulo: Secretaria do Meio Ambiente do Estado de São Paulo, 2002. p. 111-132.

PYŠEK, P.; PRACH, K.; REJMANEK, M.; WADE, M. Plant invasions: general aspects and special problems. Amsterdam: SPB Academic Publishing, 1995. 263 p.

PYŠEK, P.; RICHARDSON, D. M.; REJMÁNEK, M.; WEBSTER, G. L.; WILLIAMSON, M.; KIRSCHNER, J. Alien plants in checklists and floras: towards better communication between taxonomists and ecologists. Taxon, Vienna, v. 53, p. 131-143, 2004.

PYŠEK, P.; RICHARDSON, D. M. Invasive plants. In: JØRGENSEN, S. E.; FATH, B. D. (Ed.). Encyclopedia of Ecology. Oxford: Elsevier, 2008. p. 2011-2020.

RAMONEDA, F. M. M.; SOUZA, S. C. P. M. O efeito da cobertura vegetal na distribuição dos indivíduos de Livistona Chinensis (Jack) R. Br. ex. Mart. 2016. São Paulo: Instituto Florestal, 2016. (Relatório final - PIBIC/IF)

RIBEIRO, M. C.; METZGER, J. P.; MARTENSEN, A. C.; PONZONI, F. J.; HIROTA, M. M. The Brazilian Atlantic Forest: how much is left, and how is the remaining forest distributed? Implications for conservation. Biological Conservation, Boston, v. 142, n. 6, p. 1141-1153, 2009.

RICHARDSON, D. M.; BOND, W. J. Determinants of plant distribution: evidence from pine invasions. The American Naturalist, Chicago, v. 137, n. 5, p. 639-668, 1991.
RICHARDSON, D. M.; PYŠEK, P.; REJMÁNEK, M.; BARBOUR, M.G.; PANETTA, F. D.; WEST, C. J. Naturalization and invasion of alien plants: concepts and definitions. Diversity and Distributions, Stellenbosch, v. 6, p. 93-107, 2000.

SOUZA, F. M.; SOUSA, R. C.; ESTEVES, R.; FRANCO, G. A. D. C. Floristic composition of tree and shrub species of the Jaraguá State Park, São Paulo, Brazil. Biota Neotropica, Campinas, v. 9, n. 2, p. 187-200, 2009.

SOUZA, S. C. P. M.; SILVA, A. G.; FRANCO, G. A. D. C.; IVANAUSKAS, N. M. A vegetação secundária em um fragmento florestal urbano: influência de exóticas invasoras na comunidade vegetal. Revista do Instituto Florestal, São Paulo, v. 28, p. 7-35, 2016.

TABARELLI M.; MANTOVANI, W. A regeneração de uma floresta tropical montana após corte e queima (São Paulo- Brasil). Revista Brasileira de Biologia, São Paulo, v. 59, n. 2, p. 239-250, 1998

WATERHOUSE, J. T.; QUINN, C. J. Growth patterns in the stem of the palm Archontophoenix cunninghamiana. Botanical Journal of the Linnean Society, London, v. 77, p. 73-93, 1978.

WILLIAMSON, M. Biological invasions. London: Chapman \& Hall, 1996. 244 p.

XACT INFORMATION. Control of unwanted plants. Potchefstroom: Cooper Sunset Trading 100 Ltd., 2005. 238 p.

ZENNI, R. D. Manejo de plantas exóticas invasoras em planos de restauração de ambientes naturais. Cadernos da Mata Ciliar, São Paulo, v. 3, p. 17-22, 2010.

ZENNI, R. D. The naturalized flora of Brazil: a step towards identifying future invasive non-native species. Rodriguésia, Rio de Janeiro, v. 66, n. 4, p. 1137-1144, 2015.

ZENNI, R. D.; DECHOUM, M. S.; ZILLER, S. R. Dez anos do informe brasileiro sobre espécies exóticas invasoras: avanços, lacunas e direções futuras. Biotemas, Santa Catarina, v. 29, n. 1, p. 133-153, 2016.

ZILLER, S. R.; DECHOUM, M. S. Plantas e vertebrados exóticos invasores em unidades de conservação no Brasil. Biodiversidade Brasileira, Brasília, v. 3, n. 2, p. 4-31, 2013.

ZONA, S.; HENDERSON, A. A review of animal-mediated seed dispersal of palms. Selbyana, Sarasota, v. 11, p. 6-21, 1989.

ZUPO, T. M.; PIVELLO, V. R. Acompanhamento da invasão de um fragmento florestal urbano (São Paulo, SP) pela Palmeira Australiana Archontophoenix cunninghamiana H. Wendl. \& Drude. In: CONGRESSO DE ECOLOGIA DO BRASIL, 8, 2007, Caxambu. Anais... Caxambu: Sociedade de Ecologia do Brasil, 2007. p. 1-2. 